\title{
Root Development in Barley and Wheat under Different Conditions of Growth.
}

BY

\author{
WINIFRED E. BRENCHLEY, D.Sc.,
}

AND

\begin{abstract}
VIOLET G. JACKSON, M.Sc.
(Rothamsted Experimental Station).
\end{abstract}

With four Figures in the Text.

T $\mathrm{N}$ I9I 8 our attention was drawn to the occurrence of white roots in wheat growing in the field. These white roots were easily distinguished from the ordinary type by their thickness, their waxen appearance, and by a lack of lateral branches. They were noticed on plants in early spring, and it was suggested to us that they form an extra food-supplying system for the wheat plants when they are beginning their summer growth. This phenomenon, however, has been observed at Rothamsted for many years in different series of experiments when barley is grown in water cultures. The white roots are found fairly abundantly on all the plants when they are taken out of their solutions at the conclusion of the experiments, which generally occurs before the barley is fully ripe. A typical root system under these circumstances shows a number of very long roots of medium thickness, which occupy the central part of the system and branch freely throughout almost the entire length. On the outer side of the root, springing from the tillers, and therefore of later growth, are usually a number of 'white roots', which are much thicker than the others and often reach a length of several inches without bearing any laterals. Some of the longest white roots bear a few short laterals near the crown. Together with these thick roots are thin, delicate ones which begin to give off laterals while quite small, and tend to branch well down towards the tip. 'White' roots have also been observed on wheat plants in Broadbalk in early spring, occurring earlier in the farm-yard manured plot than on the unmanured. The occurrence of these white roots in such widely different circumstances as those obtaining in water and in soil cultures led us to investigate their

[Annals of Botany, Vol. XXXV. No. CXL. October, 1921.] 


\section{Brenchley and Fackson.-Root Development in Barley and}

appearance in plants at different periods of growth, and the experiments were extended to include the relations between root and shoot growth.

A considerable amount of information is available on the subject of the growth of the shoot and of the root of various crop plants, but there is not much literature dealing with the relation between shoot and root growth at various stages in the plant's history.

Experiments were carried out this year (1920) to investigate the root systems of plants growing in pots under controlled conditions and also of others growing under ordinary farm conditions in the field, and an attempt has been made to correlate shoot and root development. Wheat and barley were chosen for this investigation, both in the pot cultures and the field trials.

\section{Root System of Barley.}

\section{Pot Cultures.}

The early stages of development were obtained by sowing the grain in small glazed earthenware pots, 7 inches in height and $5 \frac{1}{2}$ in diameter, holding $6 \frac{1}{2} \mathrm{lb}$. of soil. The soil used throughout the experiment was rather heavy farm soil mixed with so per cent. of sand to lighten it. Half the pots were unmanured and half had $0.7 \mathrm{grm}$. superphosphate mixed in with the soil. In each manurial series one half of the pots were sown with wheat and the other half with barley at the rate of two grains per pot in each case. When the shoots were about $\mathrm{I}$ in. high, the weaker plant in each pot was destroyed by cutting off the shoot, since pulling up by the root would probably have disturbed the roots of the other plant. At the same time a series of cultures in large pots, height $\mathrm{I} 4 \mathrm{in}$, diameter $6 \frac{1}{2}$ in., each holding $23 \mathrm{lb}$. soil, were set up, $\frac{2}{5}$ of which were left unmanured and $\frac{3}{5}$ received $2 \frac{1}{2} \mathrm{grm} .{ }^{1}$ superphosphate per pot. Seeds were sown as before-wheat on Feb. 2I, barley on March 5 . Some weeks later, on April 6, sodium nitrate and potassium sulphate were applied as top-dressings to some of the pots, the final series of manuring being as shown in the following table:

$\begin{array}{cc}\text { Series I } \\ \Rightarrow & 2 \\ " & 3 \\ " & 4 \\ " & 5\end{array}$

Unmanured.

$$
\begin{gathered}
\text { Superphosphate } \\
\text { + sodium nitrate. } \\
" \quad+\text { sodium nitrate. } \\
\quad+\text { potassium sulphate. }
\end{gathered}
$$

Wheat sown Feb. 21, weight of grain $0.05^{-0.06}$ grm., top-dressed April 6. Barley " March 5,

The scheme adopted was periodically to examine the root growth of two plants with each type of manuring. The small pots were examined 
weekly, the large ones fortnightly, but later the period was lengthened, as the supply of plants threatened to run short before maturity was reached. For convenience of working, wheat and barley were dealt with in alternate weeks.

As soon as the seedlings appeared above ground in the small pots, which was about ten days after sowing, two unmanured pots and two superphosphate pots were very carefully emptied. The plants were extricated without damaging the roots, and the latter were then washed in water with a camel's-hair brush. Sketches of the plants were made and full notes taken on the condition of root development. The following weeks this proceeding was repeated until all the small pots were emptied. These early plants were not weighed, as it was not at first realized what a large amount of root growth would be obtained under the given experimental conditions. By the time the small pots were finished the top-dressings had been applied to the large pots, and henceforward two pots from each manurial series were dealt with at a time, making ten plants in all each week. It was of course impossible to empty out these large pots without damaging the roots, and therefore a jet of water was used to wash away the soil without injury to the delicate roots. In the method adopted the pots were placed in a horizontal position on a stand of convenient height, with the mouth projecting over a large bath, and the soil was washed out of the pot by means of a small but fairly strong jet of water. Most of the soil was caught by the bath, thus preventing the troubles of drain stoppage, and if by chance a portion of the roots became detached it was more easily reclaimed than it would have been if the washing out were done directly over a drain. In using the jet of water great care had to be exercised to avoid dislodging the soil in the middle of the pot first, for if this happened the superimposed soil collapsed suddenly and in so doing tore away several of the roots. After removal from the pots the roots were carefully freed from adhering particles of soil with a camel's-hair brush, and were then disentangled and measured under water to prevent any shrinkage due to drying up. The length of the shoot and the number of tillers were noted and after drying the roots and shoots were weighed separately.

A well-developed root system of barley examined half-way through growth showed two distinct types of root: $(a)$ long, much-branched roots, forming the bulk of the system, and (b) short, white, unbranched roots.

(a) Branched roots. Seven weeks after sowing the length and number of the branched roots varied considerably with the type of manuring, the highest number occurring with the superphosphate, and the lowest with the unmanured plants. In the more heavily manured plants laterals were well developed and tended to become concentrated in the upper 10-I 2 in. of the roots, while in the unmanured and the nitrate only plants the laterals were not so well developed and were much more scattered. As growth proceeded, 


\section{Brenchley and Fackson.--Root Development in Barley and}

this concentration of the laterals in the upper part of the roots was noticeable in all the manurial series. In the early stages of growth the addition of superphosphate seemed to bring about considerable development of laterals, but in the unmanured and in the nitrate plants laterals were fewer, they were less branched, and apparently bore fewer root-hairs than those receiving superphosphate. In the unmanured plants this condition remained throughout the experiment, but in the plants receiving nitrate the laterals became very coarse and were much concentrated in the part nearest the grain, giving a crinoline effect. This effect was produced by the formation of a large number of extra long laterals along the few inches of root near the grain, rather than by the formation of numerous roots practically all at one point. The plants receiving superphosphate and nitrate also showed this crinoline effect very strongly. At later stages of growth the roots of the nitrate and of the superphosphate and nitrate-treated plants had become so densely matted together that it was impossible to decide whether the crinoline effect was still present or not. At maturity there was certainly no such effect observable in the nitrate only plants, for by this time the total amount of root system was very much smaller than it had been at earlier stages. In the superphosphate and nitrate plants, however, the crinoline effect was still observable at the last examination. The plants with superphosphate and potash also showed some crinoline effect, but this was not as marked as that of the nitrate plants. A noticeable feature in the potash series was the thickening and stiffening of the roots near the crown, where the laterals also were of a coarser type than elsewhere. This stiffening caused the roots to stand well away from the plant, and even when they were taken out of water the roots showed no tendency to collapse against each other, as they did in plants from all the other manurial series. As this did not occur in the plants receiving superphosphate only, it was presumably an effect due to the potash. Again this effect was not observed at maturity, when the root system was very much reduced in size.

(b) 'White' roots. The plants were first examined eleven days after sowing, when the shoots were about half an inch above the soil. Seven or eight roots were present, the longest being about 5 in.; lateral branches had not made their appearance, but root-hairs were very plentiful, especially near the grain. Seven days later laterals had developed on all the roots, and as growth proceeded there was an increase in the number and length of the roots and a similar increase in the development of laterals. It was not until four weeks after sowing that the first 'white' roots made their appearance. At this time the shoots of the unmanured plants were about II in. long with no tillers, the main roots being about $I 5^{-20}$ in. One plant examined showed a root about $\frac{1}{4}$ in. long coming from the base of the grain, of a much thicker nature than any of the others and of a dead white colour 
with a waxen appearance. The superphosphate plants were well ahead of the unmanured; the shoots were longer and had commenced to tiller, and the root system was much stronger. Each plant showed one thick white root over $1 \frac{1}{2}$ in. in length. At this time the top-dressings of sodium nitrate and potassium sulphate were applied, and a fortnight later in all the manurial series the 'white' roots had become more numerous, and some had reached a length of several inches. In many cases they came off from the node just above the grain. In the unmanured and in the nitrate series the number and average length of the ' white' roots were very much the same, and they remained comparable for the next four weeks, i.e. until eleven weeks after sowing. With superphosphate, root growth was encouraged from a very early date, and as time went on the differences between these plants and the unmanured were accentuated, as is seen by comparison of the number of white roots at different periods in the following table (I).

\section{TABLE I. \\ Barley (sozen March 5).}

Showing average number of white roots at different dates.

\begin{tabular}{|c|c|c|c|c|c|c|}
\hline $\begin{array}{l}\text { Age of } \\
\text { plant. }\end{array}$ & $\begin{array}{c}\text { Date of } \\
\text { observation. }\end{array}$ & Unmanured. & $\mathrm{NaNO}_{3}$. & Superphosphate. & $\begin{array}{c}\text { Superphosphate } \\
+\mathrm{NaNO}_{3} .\end{array}$ & $\begin{array}{c}\text { Superphosphate } \\
+K_{2} \mathrm{SO}_{4}\end{array}$ \\
\hline Weeks. & April 20 & $3 *$ & & 6 & & \\
\hline 9 & May 4 & $\begin{array}{l}3 \\
7\end{array}$ & $\begin{array}{l}4 \\
4\end{array}$ & 15 & $1 \stackrel{3}{8}$ & $\begin{array}{r}5 \\
\mathrm{I} 5\end{array}$ \\
\hline I I & May i 8 & I7 & I7 & 22 & 25 & 24 \\
\hline I3 & June 8 & 0 & 0 & 0 & 0 & 0 \\
\hline
\end{tabular}

At first the plants with superphosphate and nitrate gave lower numbers of white roots than did the superphosphate alone, but later the former drew ahead. With superphosphate and potash the numbers were much the same as with the superphosphate alone (see Table I). The length reached by the white roots did not seem to be affected by the type of manuring, but ranged up to about $g$ in., according to the age of the roots.

These white roots do not retain their unbranched character throughout the life of the plant, but after some time they put out laterals and ultimately approximate to the general root system. When all the plants were eleven weeks old, a marked change was noticed in the formation of the root system. The thick white unbranched roots were no longer present, though a certain number of short roots occurred which were thin and showed incipient laterals. With the superphosphate and nitrate manuring a few thick white roots were still noticeable, all of which carried laterals well down their length, while with the superphosphate and potash a good number of long, thick, white roots with a number of laterals in the upper 4 in. were noticed. From this time onwards the 'white' roots entirely 
disappeared, but a large number of thin roots bearing only incipient laterals were present until three weeks before harvest time. When the last plants were taken out, all the roots showed normal branching.

Considering the manurial series together, a feature common to them all is the steady rise in the numbers of the white unbranched roots for the period extending from the 7 th to the IIth week after sowing and their disappearance after that time.

Relative growth of root and shoot in Barley. The relative growth of the root and shoot, as measured by the amount of dry matter produced, shows an interesting correlation with the morphological development of the root at different periods of growth (Table II and Fig. I).

For the first six or seven weeks growth was very slow, and the plant seemed to be laying the foundations for future development. The actual difference between the dry weight of root and shoot after seven weeks was not very great, but by this time the beneficial effect of the superphosphate which was added at the beginning was already marked. During the next fortnight a rapid increase in growth took place, and a still further increase occurred afterwards, the latter being more marked in the shoot. In some cases the shoots continued to increase in dry weight till harvest time, though in others a slight fall was indicated towards the end. The roots, on the contrary, reached their maximum weight long before the harvest, the exact

period varying with the manures applied. The unmanured roots, as would be expected, made less growth than any others: they increased in dry matter for about seventeen weeks and then gradually lost weight till harvest, seven weeks later. The biggest root growth was given by sodium nitrate, much the same result being obtained whether superphosphate was present or not. The general effect of manuring was to hasten the rise to a maximum, which was reached in most cases after fourteen weeks' growth, though in unmanured soil and in the presence of superphosphate and sodium nitrate together increase continued for seventeen weeks. From the maximum a fairly rapid and steady decrease in dry matter took place until at harvest time most of the roots, with all types of manuring, were of much the same weight and were reduced to what they had been after only ten or eleven weeks of growth.

This decrease in weight appears to be associated with an actual loss of root material due to decay or to migration into the aerial parts. At the time the roots were at their maximum they were strong and well developed, but afterwards at each successive washing out it was obvious that depreciation was taking place, till by harvest time the roots were very poor and feeble. ${ }^{1}$

1 The superphosphate and sodium nitrate root seemed to be an exception to this, as the last plant observed had a very massive and heavy root. Unfortunately only one plant was available at this date, but it is quite possible that this may have been an exceptional one, as those observed three 


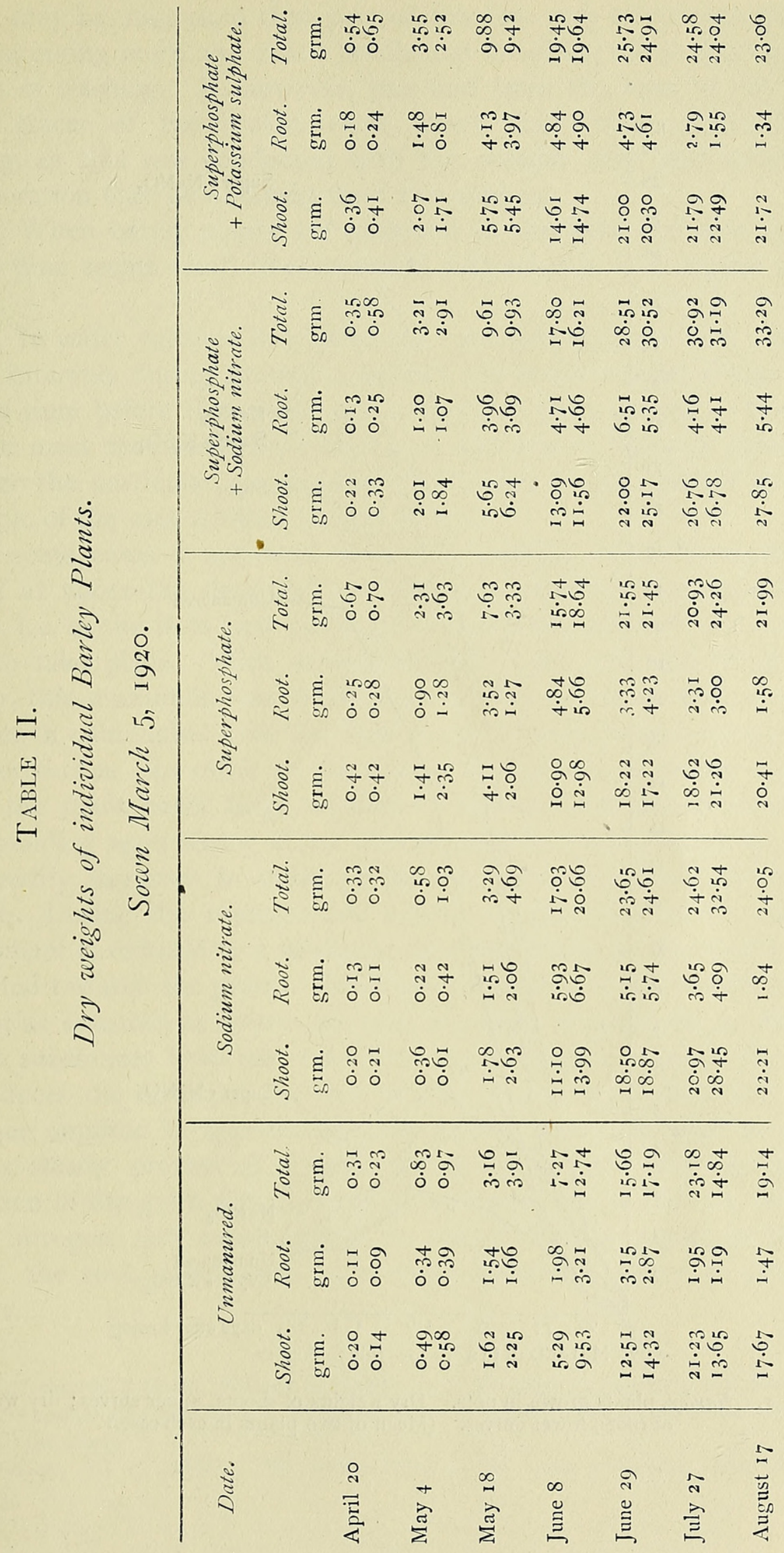




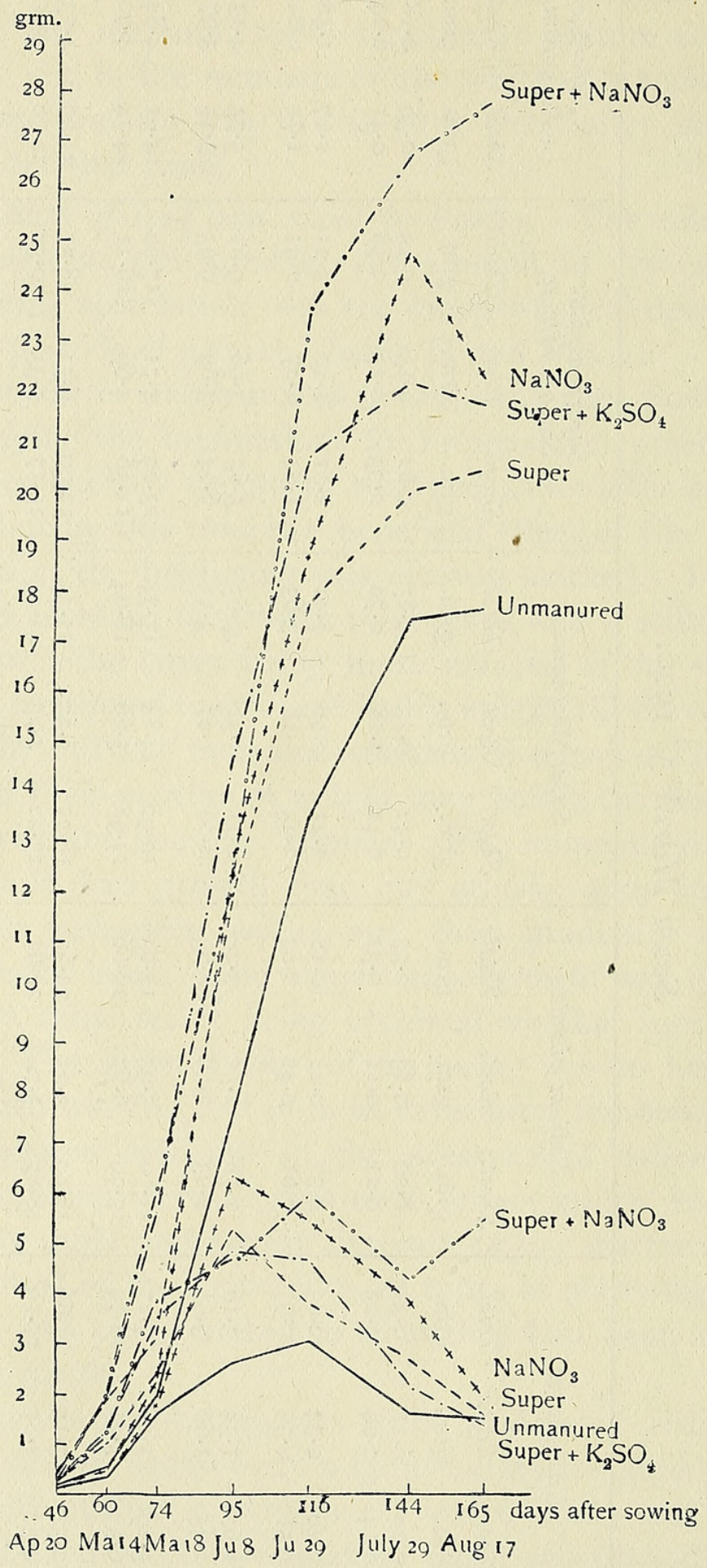

FIG. I. Barley, plants grown in pots. Dry weights of shoots, upper curves; dry weights of roots, lower curves. (Mean of two plants in each case.) 
It may be suggested that part of the loss may have been due to the roots becoming more and more brittle and breaking off at the ends in the process of washing. If, however, this had been the case to any marked degree traces of the broken roots would have been observed during washing, as this was conducted with the utmost care and watchfulness. Corroboration may be obtained from two sources.

(a) When barley plants are observed in the field the root system at harvest time seems small in comparison with what it is at earlier stages of growth.

(b) In water cultures in which peas were grown, dried and weighed at regular intervals during growth, a definite fall in the weight of the root set in some time before the plants had completed their growth. The fall in this case must necessarily have been real, and due to decay of plant tissues, as under the particular experimental conditions it was possible to recover the whole of the root without danger of loss.

In some cases it appeared that the maximum root development was reached at about the time that the ears were ready to emerge from their sheaths, i.e. at the time that pollination and fertilization of the ovule were about to take place. With superphosphate alone and with nitrate alone, however, this maximum was reached somewhat earlier, so that apparently root growth culminated with the final stage of preparation by the plant for grain formation. In other words, during the period of purely vegetative growth the plant needs large supplies of nitrogen and ash constituents to aid in building up a strong shoot in readiness for grain formation, and the root steadily increases in order to be able adequately to cope with this demand. During the reproductive phase, on the other hand, vegetative development is reduced to a minimum, and the whole of the plant's energy is diverted towards the grain. Although nitrogen and ash constituents are now just as essential as before, the area of supply is increased, as migration of these substances from the straw into the grain goes on from the outset. ${ }^{1}$ This reduces the strain on the root, and as such a large absorbing area is no longer required it appears that the excess provision may be got rid of by a steady process of decay. Analyses indicate that by the time desiccation of the grain sets in, about three weeks before harvest, the whole of the nitrogen and ash required is already in the plant, so that the work of the root, other than as a water-absorbing organ, is practically complete.

weeks earlier showed a similar decrease in weight to all the other types, and if this decrease had continued its normal course to the end the superphosphate and nitrate plants would have fallen into line with all the others.

1 Brenchley, W. E. (1912): The Development of the Grain of Barley. Ann. Bot., xxvi, pp. 9 I4-I9. 
Shoot/root ratio. The relations between the root and shoot at different periods are well brought out by a comparison of the shoot/root ratios.

TABLE III.

Shoot/Root Ratios. Barley.

\begin{tabular}{|c|c|c|c|c|c|}
\hline Date. & Unmanured. & $\begin{array}{l}\text { Sodium } \\
\text { nitrate. }\end{array}$ & $\begin{array}{c}\text { Super- } \\
\text { phosphate. }\end{array}$ & $\begin{array}{c}\text { Super- } \\
\text { phosphate } \\
\text { Sodium } \\
\text { nitrate. }\end{array}$ & $\begin{array}{c}\text { Super- } \\
\text { phosphate }+ \\
\text { Potassium } \\
\text { sulphate. }\end{array}$ \\
\hline \multirow[t]{2}{*}{ April 20} & $\mathrm{I} \cdot 75$ & $I \cdot 56$ & I. 69 & $I \cdot 70$ & I.98 \\
\hline & I. 58 & I.92 & $1 \cdot 52$ & $I \cdot 32$ & I. 75 \\
\hline \multirow[t]{2}{*}{ May 4} & $I \cdot 45$ & $I \cdot 59$ & $\mathrm{I} \cdot 55$ & 1.68 & 1.40 \\
\hline & $I \cdot 5^{2}$ & $\mathrm{I} \cdot 45$ & I. 84 & $I \cdot 7^{2}$ & $2 \cdot$ I I \\
\hline \multirow[t]{2}{*}{ May I 8} & I.06 & I. 18 & I.I 7 & $I \cdot 43$ & I. 39 \\
\hline & $I \cdot 36$ & I. 28 & I. 62 & I. 69 & I. 37 \\
\hline \multirow[t]{2}{*}{ June 8} & 2.67 & $\mathrm{I} \cdot 87$ & $2 \cdot 25$ & $2 \cdot 78$ & 3.02 \\
\hline & $2 \cdot 97$ & $2 \cdot 10$ & $2 \cdot 30$ & $2 \cdot 4^{8}$ & 3.01 \\
\hline \multirow[t]{2}{*}{ June 29} & 3.97 & 3.59 & $5 \cdot 47$ & $3 \cdot 38$ & $4 \cdot 43$ \\
\hline & 4.99 & $3 \cdot 29$ & 4.07 & $4 \cdot 70$ & $4 \cdot 4 \mathrm{I}$ \\
\hline \multirow{2}{*}{ July 27} & 10.89 & $5 \cdot 75$ & 8.07 & $6 \cdot 43$ & $7 \cdot 8 \mathrm{I}$ \\
\hline & I I $\cdot 48$ & 6.97 & $7 \cdot 10$ & 6.08 & I $4 \cdot 49$ \\
\hline August I 7 & 12.02 & 12.05 & 12.95 & $5 \cdot 12$ & 16.23 \\
\hline
\end{tabular}

For about a month after rapid growth set in both root and shoot grew at much the same rate. If anything, root growth was the stronger, as the shoot/root ratio had a tendency to fall throughout the period. From this time on the shoot grew far more rapidly than the root, and the ratio immediately increased, to be followed by a still further rise after the weight of the root had reached its maximum and had begun to fall. With superphosphate and nitrate, either alone or combined, the disproportion between shoot and root was less marked than with no manure or mixed minerals (superphosphate and potassium sulphate). (See Table III and Fig. 2.)

The change in the relative ratio of growth of root and shoot is closely associated with the change in the morphological structure of the roots. The 'white' roots, described earlier in the paper, were markedly in evidence for the first eleven weeks of growth, during which the shoot and root were growing at much the same rate, and the shoot/root ratio remained practically constant or showed a slight fall. With the increase in the rate of shoot growth and the consequent rise in the shoot/root ratio came the disappearance of the 'white' roots-the change being quite sharply marked in every case. This change occurred at the same time with all the systems of manuring, although the actual amounts of previous growth were so different. Possibly this was associated with weather conditions. Prior to this time, about May 18 , the mean maximum temperature did not rise above $60^{\circ} \mathrm{F}$, nor the mean minimum above $45^{\circ} \mathrm{F}$. After this the mean maximum did not fall below $60^{\circ} \mathrm{F}$, and the mean minimum was usually 
over $45^{\circ} \mathrm{F}$. Also an extra amount of sunshine occurred just at this time, 82.5 hours for the week (the maximum for the whole season), and this may have helped to cause such a striking and sharply marked change.

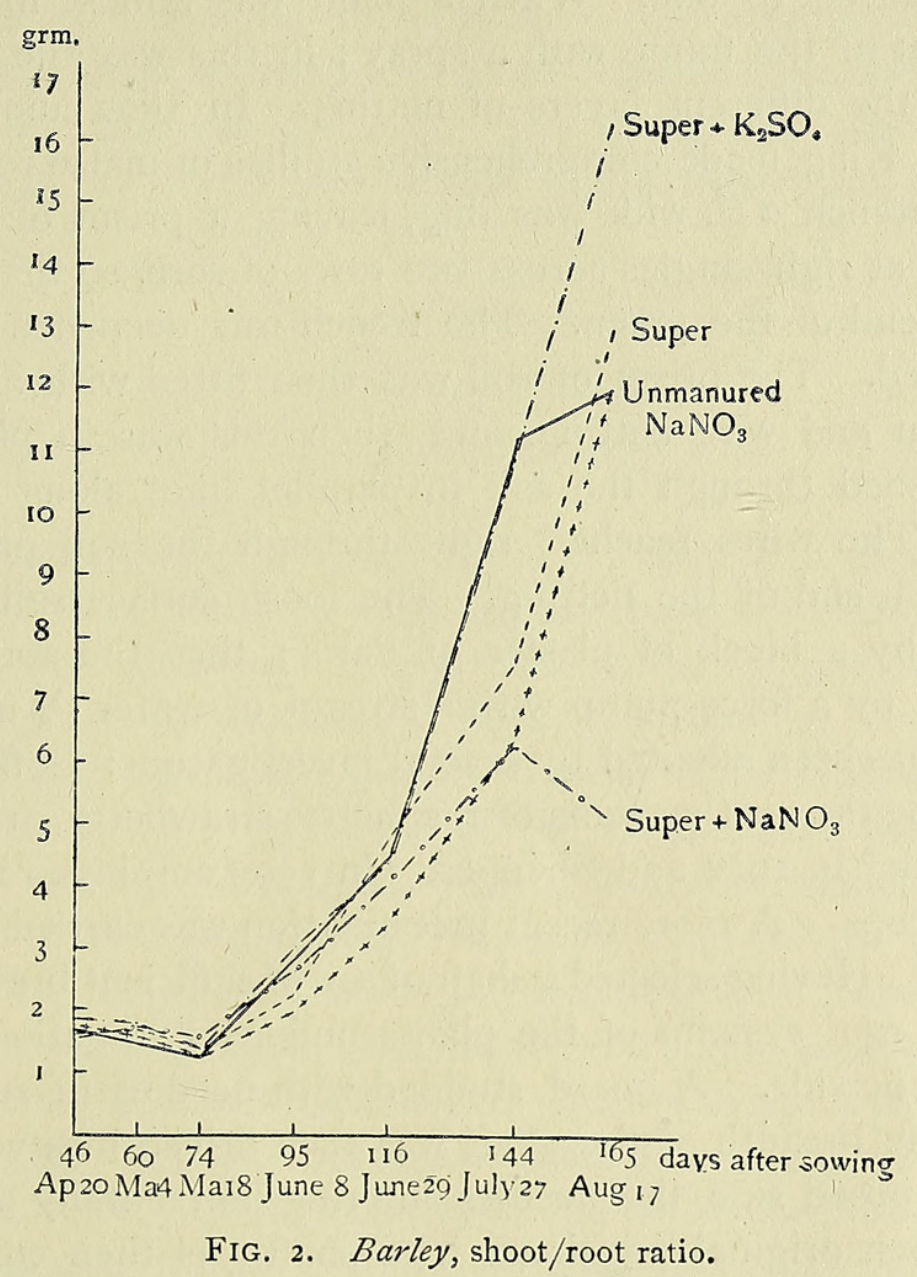

Field Trials.

Methods used by earlier workers. Various methods of root investigation have been devised at different times, the most straightforward being to wash out the roots by means of a jet of water under pressure. Hays, ${ }^{1}$ working at Minnesota in 1889 , used this method and was able to obtain useful information on the development of the roots of maize plants. A few years later, ${ }^{2}$ I 893 , he used a more complicated method by which he was able to extricate the plant with its roots in almost the exact position in which they grew. This was done by means of a frame made of I in. gaspipe, which was sunk into a hole just large enough to take it. The frame

1 Hays, W. M. : Corn, its Habits of Root Growth . . . Suckers. Agr. Expt. Sta., Univ. Minnesota, Bull. 5, pp. 5-33, 1889.

2 Ibid.: A Device for Illustrating the Root Growth of Plants. North Dakota Sta., Bull. Io, pp. 47-9, Pl. I, I 893 . 


\section{Brenchley and Fackson.-Root Development in Barley and}

was filled with sifted soil and at each 2 or 3 in. a square of 2 in. wire netting was placed and each square wired to the corner parts of the frame. Two or three seeds were sown in each frame, and the seedlings when well established reduced to one. When a plant was almost mature, the soil was washed out of the frame with a spray; in this way the roots were left spread out in the different layers of netting. In 1892 another American worker, ${ }^{1} \mathrm{~F}$. H. King, made comprehensive studies of maize roots growing in the field. A trench $2 \mathrm{ft}$. wide was dug, leaving a prism of soil $\mathrm{I} f \mathrm{ft}$. thick and extending at right angles across two rows of corn, so that a hill of corn stood at each end of the prism. The trench was deepened until all roots had been passed. The prism of soil was then fitted with a cage made of galvanized iron and wire netting, and when this was in place sharpened wires were pushed through the soil in parallel lines along the meshes of the netting. The wires reached right through the soil prism and were fastened at each end of the netting. The loose surface soil was taken off and replaced by a block of plaster of Paris; then the soil was removed from the cage by a force-pump with a stream of water $\frac{1}{16}$ in. in diameter. This method has been adopted by several investigators; Goff ${ }^{2}$ in I 897 used it for examining the root systems of raspberry, strawberry, grape, and apple, while Ten Eyck ${ }^{3}$ in 1900 and Shepperd ${ }^{4}$ in 1905 employed the method for various field crops. A more recent investigation was carried out by Maschhaupt in I9I $5 .{ }^{5}$ Having selected a shaft of soil of sufficient breadth and depth to include the root systems of the plants under investigation, he cut away the soil from one side. A board studded with needles of sufficient length to penetrate the breadth of the shaft was then driven in a vertical position against the exposed side, the needles entering horizontally and so keeping the roots in their original position. The shaft was then cut loose on the opposite side by driving down to the desired depth a piece of sheet iron, and the soil was carefully washed away from the roots.

Rothamsted methods. The field trials which were started here were intended for comparison with the pot cultures, and five plots were set out for wheat and five for barley. Their arrangement is illustrated in the accompanying table, the manurial system being exactly the same as that followed in the pot cultures. The wheat and barley were sown on Feb. 25, and twelve days later several plants were dug up, brought down 1893.

1 King, F. H. : Natural Distribution of Roots in Field Soil. Wisconsin Sta. Report, I892 and

2 Goff, E. S. : A Study of the Roots of Certain Perennial Plants. Wisconsin Sta. Report, 1897, pp. $286-98$.

3 Ten Eyck, A. M. : A Study of the Root Systems of Cultivated Plants grown as Farm Crops. North Dakota Sta. Bull. 43, I900, pp. 535-50.

4 Shepperd, J. H. : Root Systems of Field Crops. Ibid. 64, 1905.

5 Maschhaupt, J. G.: Root Systems of Agricultural Plants. Verslag Landbouwk. Onderzoek. Rijkslandbouwproefstat. (Netherlands), No. I6 (I9 I 5), pp. 76-89. 
to the laboratory, washed in water with camel's-hair brushes and sketched. This was repeated twice at intervals of about ten days, by which time the plants were too large to be handled in this way. The crop of both wheat and barley was very poor, as not only were bird attacks very severe, but the ground was almost covered with weeds, chiefly Papaver rhoeas, Matricaria inodora, and Sonchus arvensis. The barley crop was better than the wheat, and when the barley was almost ripe a trench was dug across the

$\begin{array}{clc}\text { Wheat. } & \text { Barley. } \\ \text { I } & \text { Superphosphate only } & 6 \\ 2 & \text { Unmanured } & 7 \\ 3 & {\text { Superphosphate }+\mathrm{NaNO}_{3}}_{\mathrm{NaNO}_{3}} & 8 \\ 4 & \mathrm{Nuprphosphate} \mathrm{K}_{2} \mathrm{SO}_{4} & 9 \\ 5 & \text { Superphos }\end{array}$

plot receiving superphosphate and the unmanured plot ( 6 and 7 in table). An attempt was then made to wash out the roots with the spray from an ordinary spraying machine. Very little root system had developed, probably owing to the extremely poor condition of the soil. It was therefore decided to examine the roots of some of the ordinary farm barley, and another trench was dug in one of the fields where there was a good crop of unripe barley. The root systems here were rather better than on the experimental plot, but it was exceedingly difficult to wash them out without breaking the roots, for the soil was very hard; about 2 in. at the surface were moderately friable, but below that came layers of very clayey soil which became a sticky mass when water was sprayed on to it. By examining the sides of the trench it was found that very few roots penetrated below the top 2 in. or 3 in. and none appeared below the 6 in. level. Another method for obtaining the roots was then tried. A small cluster of healthy plants was chosen and a 12 in. cube of soil dug out, with the selected plants in the middle of the cube. The solid block was transferred to a box which just held it and brought down to the laboratory, where the rogots were washed out in exactly the same way as those in the pot cultures. Plants from ground which had received farm-yard manure and from ground manured with superphosphate were treated by this method, and the results described below.

\section{Barley. Growth of Roots in the Field.}

The field barley was first examined twelve days after sowing. At this time the shoots were not visible above ground, but each plant showed six or seven roots ranging from $\frac{1}{2}$ in. to $I$ in. in length. Twenty-one days later, i. e. thirty-three days after sowing, the number of roots was much the same, $6-8$, but the length had increased to about $4 \frac{1}{2}$ in. and laterals were developing. The superphosphate plants showed a rather 
better development of laterals than did the unmanured, but no other differences, either in size or general appearance, could be observed. The original intention was to examine the field roots periodically, but it was found impossible to do this and to carry on the root washing at the laboratory at the same time. Accordingly the trench method for examining the roots was not attempted until August, I68 days after sowing. At this time the barley was mature, and very little root system was found either in the unmanured or in the superphosphate plots. This may have been due to several causes; possibly the root system had been better earlier in the season, but the amount of root had decreased as the grain matured, a condition similar to that found in the pot cultures. The conditions of growth were as follows: The tilth was poor and the soil was in a very starved condition, no manure having been applied for years, and the clayey subsoil approached very near the surface. These conditions may easily have affected the roots adversely. Several of the larger roots were traced to their tips and most of their laterals were found to be perfect, but few were longer than $\frac{1}{2}$ in., nor were they branched. The majority of the roots were confined to the upper few inches of the soil, the roots running down at a slight angle to a depth of 3 in. or 4 in. When the poor root development was discovered the experimental plots were abandoned and the ordinary farm barley was examined as described above. This soil was in better condition than that on the experimental plots, and the barley was still in the green stage. About four plants grew together in the drill, giving the appearance of one tillered plant, whereas in reality very few of the plants showed any tillering. The root system was mostly confined to the top $2 \mathrm{in}$. of soil ; some roots ran down obliquely into the soil, and a few went down vertically, but none of them were observed to reach below the top 6 in.

The plants washed out from the cubes of soil (see method above) had been manured with superphosphate. They showed 2-4 tillers per plant, and a fairly well developed root system. From each crown a number of short roots, $I \frac{1}{4}$ to $2 \frac{1}{2}$ in. long, spread out in all directions, penetrating to a depth of $\mathrm{I}$ in., while a few roots were longer, much branched, and ran down obliquely to about 8 in. The greater part of the root system, however, was again in the top 2 in. Each plant showed one or two roots which had rotted back to a point above 5 in., which would correspond to a depth of 3 to $4 \mathrm{in}$. in the soil; probably the root here entered a bad stratum, which could not be penetrated. Some rather thicker and lessbranched roots were observed coming from the node, while the finer, more branched roots came from the grain. The plants grown with farm-yard manure were much better than any of the previous field specimensa typical plant having about seven tillers and many long roots with abundant laterals concentrated in the upper 5 in. of the root. There were 
no roots here comparable to those found in the superphosphate plants, where the ends had become rotten. This may be due to the better tilth obtained in a soil treated with farm-yard manure. Several of the roots penetrated to a depth of 9 in., and again it was observed that the roots coming off from the node were rather thicker and less branched than those coming from the grain.

\section{Root System of Wheat.}

\section{Pot Cultures.}

In wheat, as in barley, a strong root system developed, the types being more or less similar except with regard to the behaviour of the white roots. Nine days after sowing, when the shoots were about $\frac{1}{2}$ in. long, the roots of both the unmanured and the superphosphate plants were very similar. A typical plant possessed 3 roots up to 4 in. long, with abundant root-hairs. Five weeks after sowing the unmanured plants were found with 4 , and the superphosphate with 5 roots, the longest of which in both cases reached $2 \mathrm{I}$ in. These numbers are rather lower than those obtained in the barley plants, where 7 or 8 roots were developed in seedlings 5 weeks old, but the maximum length of root was the same for both wheat and barley. Lateral development was consistently stronger in all the manured plants than in the unmanured, and in all series the laterals showed a tendency to concentration in the upper I4-I6 in. of the rootsa tendency which was also very noticeable in all the barley series. The nitrate plants here did not show the crinoline effect which was so noticeable in the barley manured with nitrate, but the roots of the wheat receiving potash were very similar to the corresponding barley roots, for near the crown the roots of the potash plants were very woody and stood out exactly as described for barley, though to a less marked degree.

In the early stages of growth, seven weeks after sowing, there was a distinct tendency towards thickening at the ends of the long branched roots, and this tendency became more marked as growth proceeded. When the roots had attained a considerable length, it was found that they coiled up at the bottom of the pots, and the coiled up parts were always much thicker than the rest of the root, and also bore few or no laterals.

No 'white' roots appeared until seven weeks after sowing, when a few were found in the more heavily manured plants. Later, they were present in all the manurial series, but in no case did they retain for very long their unbranched character, the result being that long, branched, 'white' roots were found fairly frequently. 
TABLE IV.

Wheat. (Sown February 2I.)

Showing average number of ' white' roots at different dates.

\begin{tabular}{|c|c|c|c|c|c|c|}
\hline $\begin{array}{c}\text { Date of } \\
\text { observation. }\end{array}$ & $\begin{array}{l}\text { No. of } \\
\text { weeks } \\
\text { after } \\
\text { sowing. }\end{array}$ & Unmanured. & $\mathrm{NaNO}_{3}$. & $\begin{array}{c}\text { Super- } \\
\text { phosphate. }\end{array}$ & $\begin{array}{l}\text { Super- } \\
\text { phosphate } \\
+\mathrm{NaNO}_{3} .\end{array}$ & $\begin{array}{c}\text { Super- } \\
\text { phosphate } \\
+K_{2} \mathrm{SO}_{4} .\end{array}$ \\
\hline April I 3 & 7 & I & 2 & 2 & I & 3 \\
\hline April 27 & 9 & 2 & 2 & 5 & 5 & 6 \\
\hline May II & II & 3 & 4 & 7 & 8 & 8 \\
\hline June I & I4 & 9 & 7 & 13 & I 2 & 8 \\
\hline June I 5 & 16 & 18 & 16 & 14 & I 8 & 16 \\
\hline July I 3 & 20 & 2 & 3 & 2 & 0 & 2 \\
\hline August 24 & 26 & 0 & o & 0 & 0 & 0 \\
\hline
\end{tabular}

The numbers of white roots reached their maximum about I 6 weeks after sowing. The superphosphate plants were lowest with average number I4, while the unmanured and the superphosphate and nitrate plants were highest with 18 . A certain number of white roots was found after this date, but when the plants were mature none was found in any of the series. Thus there is in wheat nothing to correspond to the sudden disappearance of white roots which occurs in barley about II weeks after sowing, for in wheat the decline in white root numbers coincides with the decrease in weight of the complete root system, whereas in barley the formation stops suddenly when the ratio between shoot and root growth begins to change.

Relative growth of Root and Shoot in Wheat. The general behaviour of the root and shoot of wheat at different periods of growth proved to be similar to that of barley, though the details varied with the different manurings (Table V).

For the first seven weeks growth was very slow and little difference in dry weight was observable either between roots and shoots or with different manures. During the next four weeks the amount of growth, as measured by dry weight, increased considerably, but the shoots did not seem to get away properly until after May II, after II weeks' growth. The shoots increased steadily in weight till about a month before harvest, when a slackening of the rate of growth occurred except with superphosphate and nitrate applied separately. The roots, as in barley, reached their maximum long before harvest and then steadily lost weight in every case. The striking feature of the pot cultures of wheat was the close similarity in dry weight of the unmanured plants and those receiving nitrate only, this being obvious both with roots and shoots. Also, the shoots of all plants receiving superphosphate, whether with or without other manures, were almost identical in weight for I 4 weeks, after which those receiving nitrate or potash in addition ran ahead of those with superphosphate alone. The maximum root growth was attained after about 16 weeks in all the manured plants, but the unmanured roots continued to increase in weight 


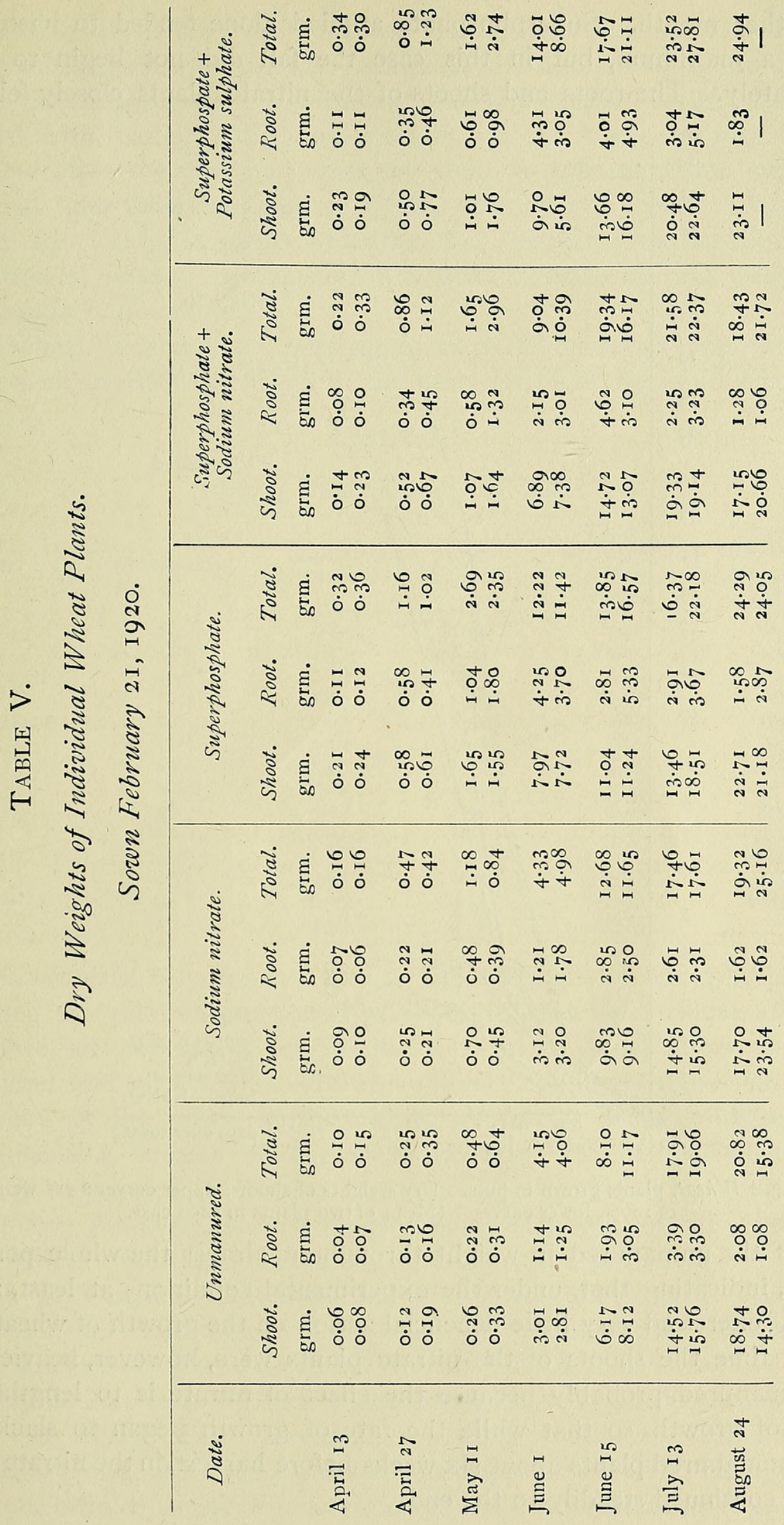


for another month. Superphosphate applied alone tended to hasten the rise to a maximum, but in this case the fall did not begin to occur immediately. The roots and shoots of the nitrate plants closely followed

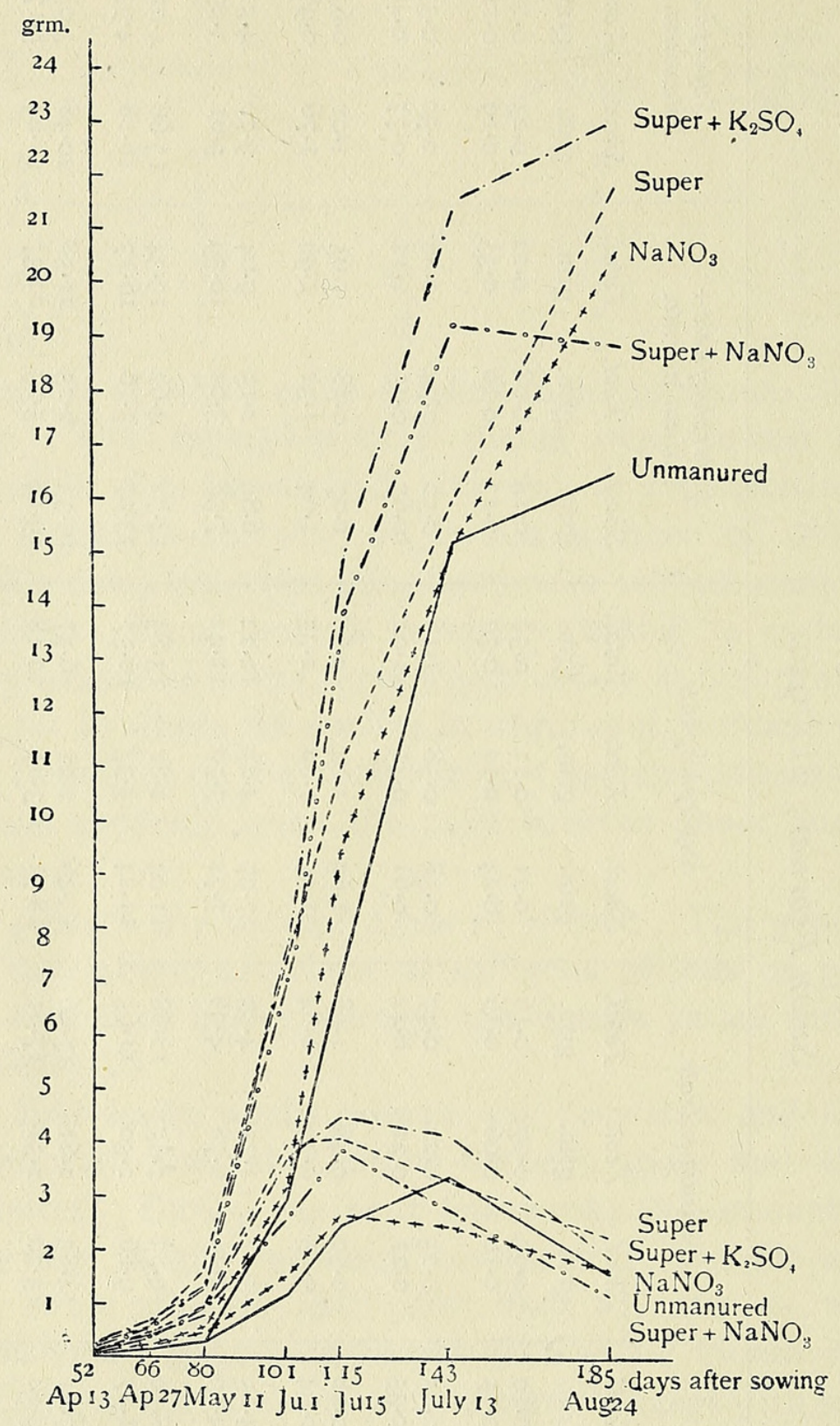

FIG. 3. Wheat, plants grown in pots. Dry weights of shoots, upper curves ; dry weights of roots, lower curves. (Mean of two plants in each case.)

those of the unmanured in weight throughout almost the whole period of growth, indicating that, under the experimental conditions at least, nitrate by itself. exercised very little beneficial action on the growth of wheat. At harvest time the shoots of the nitrate plants were, however, heavier than the unmanured, probably because the effect of nitrate is to lengthen the period of growth, so that while the rate of growth began to slacken off in the unmanured plants about six weeks before harvest, in the nitrate plants growth continued steadily to the end. 
In this case, again, maximum root development appeared to be attained almost simultaneously with the emergence of the ears from the sheaths, though with superphosphate this maximum was reached earlier, exactly as occurred with barley. With no manure, on the contrary, root growth continued after the ears had emerged, even though the latter event was somewhat later than in manured plants. As the two cereals followed one another so closely, it seems probable that the same explanation as to association of purely vegetable growth with increase of root weight will hold good in both instances.

In wheat the shoot/root ratio appeared to fall for about nine weeks, and though a slight rise took place in the next fortnight no rapid increase in

TABLE VI.

Shoot/Root Ratio. Wheat.

\begin{tabular}{|c|c|c|c|c|c|}
\hline Date. & Unmanured. & $\begin{array}{l}\text { Sodium } \\
\text { nitrate. }\end{array}$ & $\begin{array}{c}\text { Super- } \\
\text { phosphate. }\end{array}$ & $\begin{array}{c}\text { Super- } \\
\text { phosphate + } \\
\text { Sodium } \\
\text { nitrate. }\end{array}$ & $\begin{array}{c}\text { Super- } \\
\text { phosphate }+ \\
\text { Potassium } \\
\text { sulphate. }\end{array}$ \\
\hline \multirow[t]{2}{*}{ April I3 } & $I \cdot 32$ & $\mathrm{I} \cdot \mathbf{2 2}$ & I. 97 & I.9I & $2 \cdot 16$ \\
\hline & $\mathrm{I} \cdot \mathrm{I} 8$ & $I \cdot 5 \mathrm{I}$ & 2.04 & 2.23 & $I \cdot 72$ \\
\hline \multirow[t]{2}{*}{ April 27} & 0.90 & I. I 6 & I.OI & $1 \cdot 5^{6}$ & I. 42 \\
\hline & I. 24 & 1.00 & $I \cdot 4^{8}$ & $I \cdot 47$ & 1.66 \\
\hline \multirow[t]{2}{*}{ May II } & I. I 8 & $\mathrm{I} \cdot 45$ & I. 59 & I. 84 & I. 65 \\
\hline & 1.05 & $\mathrm{I} \cdot \mathrm{I} 6$ & I. 92 & $\mathrm{I} \cdot 25$ & 1.80 \\
\hline \multirow[t]{2}{*}{ June I } & 2.64 & $2 \cdot 57$ & I. 88 & $3.2 \mathrm{I}$ & 2.25 \\
\hline & $2 \cdot 24$ & $\mathrm{I} \cdot 80$ & 2.09 & $2 \cdot 45$ & I. 84 \\
\hline \multirow[t]{2}{*}{ June I 5} & 3.19 & $3 \cdot 45$ & $3 \cdot 93$ & $3 \cdot 19$ & $3 \cdot 4 \mathrm{I}$ \\
\hline & $\begin{array}{r}2.66 \\
4.28\end{array}$ & 3.66 & $2 \cdot$ I I & $4 \cdot 22$ & $3 \cdot 28$ \\
\hline July I 3 & $\begin{array}{l}4.20 \\
4 \cdot 78\end{array}$ & $\begin{array}{l}5.70 \\
6.63\end{array}$ & 4.03 & 8.60 & 0.75 \\
\hline \multirow[t]{2}{*}{ August 24} & 9.01 & 10.95 & $14 \cdot 34$ & $\begin{array}{r}5.92 \\
\text { I } 3.43\end{array}$ & $\begin{array}{r}4.50 \\
\text { г } 2.66\end{array}$ \\
\hline & 13.24 & 14.56 & $7 \cdot 37$ & I 9.54 & - \\
\hline
\end{tabular}

the ratio occurred till after this time. The effect of the superphosphate in increasing the relative proportion of shoot to root was evident at a very early date, all the ratios for the first I I weeks being above those for unmanured and nitrate plants, in which it was not much above unity. As time went on the effect of the nitrate, especially when combined with superphosphate, became more marked, showing that the shoot increased relatively more rapidly than the root. The unmanured and superphosphate plants, however, showed almost identical shoot/root ratios after the earlier period was past, indicating that the phosphate gave equal encouragement to both organs when the initial stages of growth were over (Fig. 4 and Table VI). The change in the curve of the shoot/root ratio was less sharply marked in wheat than in barley, and took place considerably earlier. This may be accounted for by the fact that wheat is typically autumn sown, is used to coping with unfavourable weather conditions, and can start into active growth with comparatively low temperature. The change in the shoot/root ratio of wheat began as soon as the mean maximum temperature 
reached $55^{\circ} \mathrm{F}$. Barley, on the other hand, is typically spring sown and needs a higher temperature before the onset of active growth can occur, a mean maximum of over $60^{\circ} \mathrm{F}$. being needed in this case.

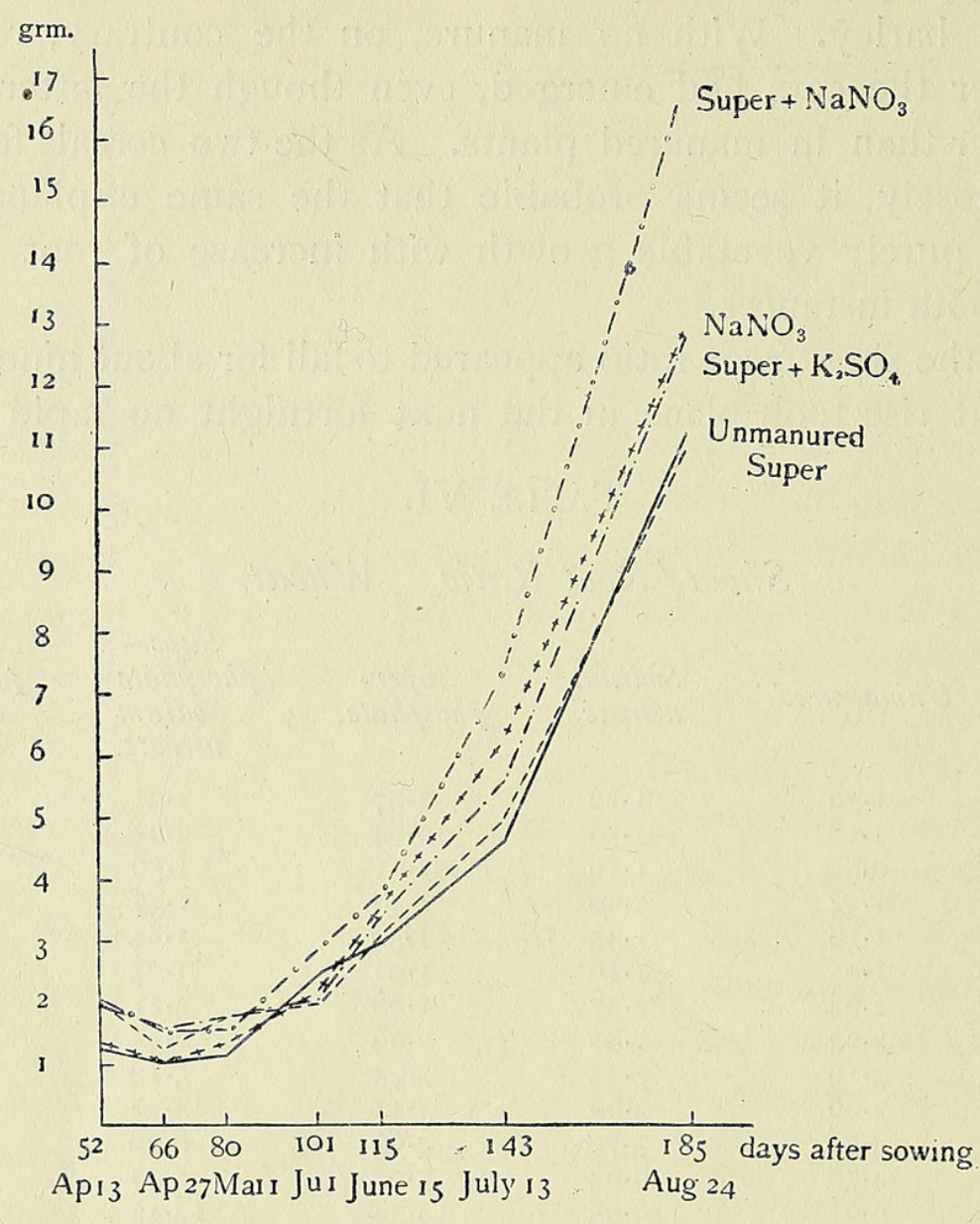

FIG. 4. Wheat, shoot/root ratio.

Field Trials.

Wheat. Growth of Roots in the Field.

Owing to pressure of laboratory work it was not possible to wash out the wheat roots from Rothamsted soil. Ten Eyck, ${ }^{1}$ however, found that the main roots grew almost vertically downwards, giving off numerous branches which made a fine network in the upper part of the soil, while the deeper roots also gave off many branches. The upper roots curved outwards before striking down into the soil, acting somewhat as brace roots, a condition of things that recalls the stiffening of the barley roots near the crown when potash manures were used.

\section{Discussion.}

At the outset of the experiment it was anticipated that some information might be gained as to the effect of various manures on the depth of rooting of wheat and barley. Shepperd ${ }^{2}$ found in his field experiments that the 
system of rooting in wheat is vertical and that wheat roots may normally run down to a depth of $4 \mathrm{ft}$., whereas barley and oats tend to show a comparatively light and shallow growth. This is common experience, but the factors which cause the difference need examination.

In the pot cultures both wheat and barley behaved in the same way with regard to the depth of penetration. The first-formed roots, branching freely, soon reached the bottom of the pots, and, continuing their growth with much less branching, coiled round the bottom and gradually formed an interlaced mat of roots in the larger plants. The pots were I4 in. deep, and for about that distance strong concentration of laterals occurred, no difference being observable between the two species. The consistent results obtained showed that the limiting factor to strong lateral production in this case was the depth of the pots; also the total length of the roots when uncoiled was much the same in both plants. It must be borne in mind that in these pot-culture experiments the soil was carefully sifted and shaken into position, but not rammed. Watering was carefully and regularly done, so that water-logging did not occur, and thus the plants were growing in a friable, well-aerated, moist soil, and did not suffer either from drought or excess of moisture. Under these favourable conditions heavy root growth was made, and barley proved able to develop as deep and strong a root system as wheat within the limits imposed by the pot. In both cases the unmanured plants had weaker roots than the manured, except that sodium nitrate failed to improve the root growth of wheat.

The field experiments, with barley, revealed quite a different state of affairs. The Rothamsted soil is heavy, and on the plots examined the tilth was poor, so that below the first inch or two the soil became very consolidated and about five inches down passed into clayey undisturbed subsoil. Under these conditions little tillering of the barley shoots occurred, and the roots when washed out were very thin and poverty stricken. The number of roots springing from each seed was small, they were thin and but slightly branched, and did not penetrate very far into the soil in a vertical direction. Instead they tended to go off at an angle, to run more or less horizontally with a downward inclination, and to take advantage of any easier passage, such as that offered by a piece of straw in the soil, a worm track, or the cavity struck out by the underground part of a strong growing weed such as Convolvulus arvensis or Cirsium arvense. The whole root system when washed out was very small and offered no comparison with that of the pot plants. The results were the same for unmanured and superphosphate plots at the time the barley was ripe and from similarly manured plots on which the barley was still green. Practical experience suggests that the roots would have been somewhat larger at an earlier stage, but the shoots showed conclusively how poor the root must have been even at its best.

It might be objected that when the roots were washed out in sitn 
many were broken off and overlooked, but that this was not the case was proved by the other experiment, previously described, in which blocks of soil containing the whole root system were removed and soaked and washed out under conditions allowing of the recovery of all broken pieces. Even under these circumstances the longest roots were only 9 in. long, and the results compared closely with those obtained in the field.

The results of these experiments may be considered from two aspects :

I. Influence of environmental conditions, other than manuring, upon root growth.

2. Influence of different types of manuring on root growth.

I. Influence of environmental conditions, other than manuring, upon root growth. The general type of the root system seems to be a more or less constant character of the species concerned, but wide variations within the type may occur through the influence of soil factors.

The environmental conditions presented by the field and pot cultures were so radically different that it is not surprising to find the root systems of both wheat and barley developed differently in each case. The lack of penetration of the barley roots into the hard field subsoil is a well-known phenomenon observable in many plants. Markle ${ }^{1}$ indicates that with desert plants a layer of soil that is difficult of penetration may cause much distortion of roots entering it. Also, roots will often turn abruptly from a layer of clay and follow a thin layer of sand or fine gravel containing much less water but more easily penetrable. This was paralleled by the behaviour of barley roots in utilizing worm-tracks or other passages when opportunity offered.

Shepperd found with maize that the roots penetrated less deeply when a layer of shale was present under the surface soil, rendering the lower layers dry and uninviting to plant roots.

Associated with the question of penetrability is that of the aeration of the soil and its effect on root growth. In experiments in India Mr. and Mrs. Howard ${ }^{2}$ found that for adequate development the roots must have abundant room in the soil for rapid growth and the space must be adequately ventilated. The rooting habit was greatly influenced by the soil conditions. Linseed, when grown on alluvium, was shallow rooted, but on deeper soils penetrated much farther. This last effect was attributed to the cracking of the upper soil, whereby the subsoil was more efficiently aerated and deeper rooting rendered possible. Similar results were obtained by Cannon, ${ }^{3}$ who states that deep-rooted plants are less dependent on good

1 Markle, M. S. (1917) : Root Systems of Certain Desert Plants. Bot. Gaz., lxiv, pp. I 77-205.

${ }^{2}$ Howard, A. and G. L. C. (1917): The Economic Significance of the Root Development of Agricultural Crops. Agr. Jour., India, Special Indian Sci. Congress Number, pp. I7-28.

3 Cannon, W. A. (1915): On the Relation of Root Growth and Development to the Temperature and Aeration of the Soil. Amer. Journ. Bot., ii, No. 5, pp. 2 II-24. 
aeration than shallow-rooted. The latter tend to branch most freely near the surface of the ground, where aeration is good and soil temperature is favourable, the deeper rooted plants being less sharply limited in growth by the soil conditions. These conclusions were fully borne out by the Rothamsted results. Barley, typically shallow-rooted, responded at once to the favourable conditions of penetrability and aeration under pot-culture conditions, and developed a root system which corresponded closely with that of the typically deep-rooting wheat. In the field, on the contrary, where the soil was badly aerated and difficult to penetrate, the barley roots were short and very poorly developed, whereas those of the wheat were apparently able to strike more deeply and develop more strongly.

Water and the available food-supply have considerable influence on development. Von Seelhorst working with rye, ${ }^{1}$ wheat, barley, \&c., found that when liberally fertilized the plants have a larger root system, the roots descending deeper into the soil and thus being able to withstand drought better.

Cannon ${ }^{2}$ states that soil temperature is another vital factor in determining the type of root growth, as roots which occupy different soil horizons in the same habitat are exposed to widely different temperatures at all seasons. In working with desert plants he found that the growthrate of roots varies with temperature, that of deep-rooted plants being more rapid at all temperatures than that of shallow-rooted. No temperature readings were taken during the Rothamsted experiments, but it may safely be assumed that as the pots were relatively small and exposed on all sides to the air, the temperature of the soil at the bottom of a pot approximated more closely to that at the top than the temperature 14 in. deep in the soil to that of the surface soil. This being the case the temperature conditions were more favourable to the growth of roots in the pots than in the field, and this, added to the other favouring conditions of aeration and penetrability, probably helped the shallow-rooting barley to strike deeply and develop a strongly branched root system.

Modestov ${ }^{3}$ carried out experiments on the root development of races of the same species, and found that different races of wheat and oats grown under similar conditions showed essential differences in the length and weight of their roots. In oats the length of the roots was in inverse proportion to the time of ripening, deeper rooting resulting in later ripening. The idea suggests itself that possibly this may hold good outside the limits of a single species, as shallow-rooted crops like barley

1 Seelhorst, C. von (1902): Beobachtungen über die Zahl und den Tiefgang der Wurzeln verschiedener Pflanzen bei verschiedener Düngung des Bodens. Jour. Landw., 1, No. I, pp. 9I-IO4.

2 Cannon, W. A. (1915) : loc. cit.

3 Modestov, A. P.: Les racines des plantes herbacées. Kornevaia sistema Travianist'kh. Rastenii., Moscow, I. N. Kushnerev, I9I5, No. I, pp. 223. See Exp. Stat. Rec., vol. xxxvi, I9I7, p. 223 . 
tend to have a shorter growing season than deep-rooted crops like wheat.

2. Influence of different types of manuring on root growth. The effect of manuring on root growth in pot culture has been considered in the earlier part of the paper, but may be summarized briefly here.

In barley the use of artificial fertilizers, whether containing $K, N$, or $\mathrm{P}$, induce a great increase in root development, this being most marked in the presence of sodium nitrate, either alone or in conjunction with superphosphate. With wheat, on the contrary, nitrogen manuring failed to bring about any increase, while the improvement with superphosphate and superphosphate + potash was far less evident than in barley.

In barley, again, the number of 'white roots' was distinctly increased by the use of superphosphate, but with wheat the ultimate number of these roots was much the same whatever the system of manuring. It is not possible to say definitely whether these results would hold good under normal conditions of cultivation, as the soil conditions presented in pot cultures are so peculiarly favourable that it would be unfair to draw from them any conclusions with regard to similar experiments in the field.

Apart from the question of depth of rooting the formation and function of the 'white roots' offer a promising field for inquiry. A comparison of the anatomical structure of the ordinary and white roots is being made by one of us, and discussion of the subject will therefore be postponed till a later paper, when more information will be available. 


\section{$2 \mathrm{BHL}$ Biodiversity Heritage Library}

Brenchley, Winifred E. and Jackson, Violet G. 1921. "Root development in barley and wheat under different conditions of growth." Annals of botany 35, 533-556. https://doi.org/10.1093/oxfordjournals.aob.a089775.

View This Item Online: https://www.biodiversitylibrary.org/item/235780

DOI: https://doi.org/10.1093/oxfordjournals.aob.a089775

Permalink: https://www.biodiversitylibrary.org/partpdf/319018

\section{Holding Institution}

Smithsonian Libraries

\section{Sponsored by}

Biodiversity Heritage Library

\section{Copyright \& Reuse}

Copyright Status: Not in copyright. The BHL knows of no copyright restrictions on this item.

This document was created from content at the Biodiversity Heritage Library, the world's largest open access digital library for biodiversity literature and archives. Visit BHL at https://www.biodiversitylibrary.org. 